\title{
Intensidade da cercosporiose da alface em cultivos convencionais e orgânicos em Pernambuco
}

\author{
Andréa Maria André Gomes ${ }^{1}$, Sami Jorge Michereff ${ }^{1}$, Rosa de Lima Ramos Mariano ${ }^{1}$, \\ Viviane Jurema Lopes Borges Rodrigues ${ }^{2}$
}

\begin{abstract}
${ }^{1}$ Departamento de Agronomia - Área de Fitossanidade, Universidade Federal Rural de Pernambuco, CEP 52171-900, Recife-PE, Brasil. E-mail: sami@ufrpe.br; ${ }^{2}$ Delegacia Federal de Agricultura de Pernambuco, Ministério da Agricultura, Pecuária e Abastecimento, 50630-060, Recife-PE, Brasil.

Autor para correspondência: Sami J. Michereff

Data de chegada: 04/10/2004. Aceito para publicação em: 31/10/2005.
\end{abstract}

\begin{abstract}
Gomes, A.M.A.; Michereff, S.J.; Mariano, R.L.R.; Rodrigues, V.J.L.B. Intensity of Cercospora leaf spot of lettuce in conventional and organic farming systems in State of Pernambuco, Brazil. Summa Phytopathologica, v.32, n.4, p.384-385, 2006.

Surveys of the intensity of cercospora leaf spot of lettuce caused by Cercospora longissima were performed in 25 conventional and 25 organic farming areas in 2 planting periods, January-April (I) and June-September (II) 2002, in State of Pernambuco (Brazil). Disease prevalence was high $(\geq 88 \%)$ in all evaluated situations. Disease severity ranged from 0.0 to $16.9 \%$ in conventional farming areas and from 0.0 to $22.5 \%$ in organic

farming areas. In both systems, disease severity was significantly higher in period I when precipitation was almost 3 times higher to that in period II. However, only in period II, significant differences in disease severity were found between farming systems, with high values in the organic system. There were no significant correlations among disease severity levels in the areas in both evaluated periods inside each farming system.
\end{abstract}

Additional keywords: Cercospora longissima, Lactuca sativa, disease assessment.

\section{RESUMO}

Gomes, A.M.A.; Michereff, S.J.; Mariano, R.L.R.; Rodrigues, V.J.L.B. Intensidade da cercosporiose da alface em cultivos convencionais e orgânicos em Pernambuco. Summa Phytopathologica, v.32, n.4, p.384-385, 2006.

Foram realizados levantamentos da intensidade da cercosporiose da alface, causada por Cercospora longissima, em 25 plantios manejados no sistema convencional e 25 no sistema orgânico, em dois períodos de plantio, janeiro-abril (I) e junho-setembro (II) de 2002 , no estado de Pernambuco. A prevalência da doença foi elevada $(\geq 88 \%)$ em todas as situações avaliadas. Nas áreas de cultivo convencional a severidade da cercosporiose variou de 0,0 a $16,9 \%$, enquanto em cultivos orgânicos de 0,0 a $22,5 \%$. Nos dois sistemas de cultivo a severidade da doença foi significativamente mais elevada no período I, quando a precipitação pluviométrica foi quase três vezes superior ao período II. No entanto, somente no período II foram constatadas diferenças significativas na severidade da doença entre os sistemas de cultivo, sendo superior no sistema orgânico. Não foram constatadas correlações significativas entre os níveis de severidade da cercosporiose nas áreas de plantio nos dois períodos avaliados, dentro de cada sistema de cultivo.

Palavras-chave adicionais: Cercospora longissima, Lactuca sativa, quantificação de doença.

A alface (Lactuca sativa L.) é uma das hortaliças mais consumidas em saladas pelos brasileiros. No ano de 2001, a Central de Abastecimento de Pernambuco, localizada em Recife, comercializou 933,7 t dessa hortaliça, oriunda principalmente do município de Vitória de Santo Antão (1). Nos últimos anos, além do cultivo em sistema convencional, a produção orgânica de alface tem se destacado em Pernambuco, principalmente nas mesoregiões da Zona da Mata e Agreste.

A cercosporiose, causada por Cercospora longissima (Cugini) Sacc., é uma das principais doenças da alface, pois afeta diretamente o órgão comercializável (3). Os sintomas da doença ocorrem inicialmente nas folhas mais baixas. As lesões têm tamanhos variados, tornando-se irregulares ou angulares, com coloração marrom clara a escura, circundadas por tecido clorótico com ponto central de coloração acinzentada. Quando a doença apresenta alta severidade, as lesões coalescem e extensas áreas do tecido foliar morrem (4).

Apesar da importância da alface, até o momento inexistem avaliações quantitativas da intensidade da cercosporiose nas principais regiões produtoras de Pernambuco, motivo pelo qual o presente 
trabalho teve como objetivo verificar a prevalência e a severidade da doença em áreas de plantio convencional e orgânico.

Nos períodos de janeiro a abril (I) e de junho a setembro (II) de 2002, foram realizados levantamentos da prevalência e da severidade da cercosporiose da alface em plantios na Zona da Mata e Agreste de Pernambuco. Em cada período foram amostradas 50 áreas de plantio, sendo 25 manejadas no sistema orgânico e 25 no sistema convencional. As áreas de produção orgânica atendiam as exigências da Instrução Normativa $n^{\text {o. }}$ 007, de 19/05/1999, do Ministério da Agricultura, Pecuária e Abastecimento. Em cada área foram selecionadas 50 plantas ao acaso, distribuídas em canteiros com espaçamento de $0,25 \mathrm{~m}$ entre plantas e fileiras. As plantas se encontravam no estádio fenológico próximo à colheita, quando os sintomas da doença são mais evidentes (4). A severidade foi determinada em cinco folhas basais, pela porcentagem de área foliar lesionada, com auxílio de escala diagramática apresentando níveis de 0 a $68 \%$ de severidade (2). A prevalência da doença foi determinada pela porcentagem de áreas com a doença em relação ao total de áreas amostradas (6).

A comparação da severidade da doença entre as áreas, considerando local de cultivo no sistema orgânico e cultivar de alface, número de plantas e número de aplicações de fungicidas, foi efetuada pelo teste de Kruskal-Wallis $(\mathrm{P}=0,05)$. O teste Wilcoxon $(\mathrm{P}=0,05)$ foi utilizado para comparação da severidade da doença entre os períodos de cultivo e sistemas de cultivo.

A prevalência da cercosporiose da alface foi elevada em todas as situações avaliadas. No sistema convencional, a prevalência foi $100 \mathrm{e}$ 92\%, nos períodos I (janeiro-abril) e II (junho-setembro), respectivamente, enquanto no sistema orgânico atingiu 100 e $88 \%$, nos mesmos períodos, respectivamente. A elevada prevalência comprova a ampla distribuição da doença na principal região produtora de Pernambuco e destaca a adaptabilidade do patógeno às condições ambientais e ao hospedeiro.

Nas áreas de cultivo convencional, a severidade da cercosporiose variou de 0,8 a $16,9 \%$ no período I e de 0,0 a $2,4 \%$ no período II. Foram constatadas diferenças significativas $(\mathrm{P}=0,05)$ para médias de severidade entre os períodos I ( $8,3 \%)$ e II $(0,8 \%)$. Nas áreas de cultivo orgânico, a severidade da doença variou de 0,1 a $22,5 \%$ no período I e de 0,0 a $15,1 \%$ no período II. Os níveis médios de severidade nos períodos I ( $7,0 \%)$ e II $(2,0 \%)$ diferiram significativamente entre si.

A maior severidade da cercosporiose no período I, nos dois sistemas de cultivo, pode estar associada aos níveis pluviométricos, uma vez que nesse período a precipitação total foi quase três vezes maior (434,2 mm) que no período II (165,7 mm), enquanto os valores médios de temperatura $\left(26,4\right.$ e $\left.27,8{ }^{\circ} \mathrm{C}\right)$ e umidade relativa do ar $(90,1$ e $88,3 \%$ ) foram bastante similares nos dois períodos de avaliação. Além do efeito de molhamento foliar, que propicia as condições ideais para germinação dos conídios de C. longissima pela imersão em água (5), a chuva também participa no processo de disseminação do inóculo do patógeno entre plantas, através de respingos (4).

Não houve diferença significativa para as médias de severidade da cercosporiose entre os sistemas de cultivo convencional $(8,3 \%)$ e orgânico $(7,0 \%)$ no período I, o mesmo não sendo constatado no período II, quando a severidade foi significativamente superior no sistema orgânico (2,0\%) em relação ao convencional $(0,8 \%)$.

Considerando o local de cultivo, no sistema convencional foram constatadas diferenças significativas entre as médias de severidade da cercosporiose da alface somente no período I, quando o município de Vitória de Santo Antão (Zona da Mata) (9,1\%) destacou-se em relação à Chã Grande (Agreste) (5,0\%). No sistema orgânico, os locais de cultivo não diferiram entre si quanto aos níveis de severidade da doença nos dois períodos avaliados.

Foram constatadas diferenças significativas entre as médias de severidade da cercosporiose entre as cultivares de alface somente no sistema de cultivo orgânico, no período I. Nessas condições, a cultivar Verdinha (grupo Lisa) apresentou níveis de severidade significativamente inferiores $(0,7 \%)$ aos observados nas cultivares Verônica (grupo Crespa) (7,7\%) e Lucy Brown (grupo Americana) (10,6\%). Quando comparados os sistemas de cultivo, a severidade da cercosporiose na cultivar Verdinha foi significativamente superior no convencional $(9,3 \%)$ em relação ao orgânico $(0,7 \%)$ no período I, o mesmo não sendo constatado em relação às cultivares Lucy Brown e Verônica, também plantadas nos dois sistemas. No período II essas cultivares não apresentaram variações significativas nos níveis de severidade da doença em função do sistema de cultivo.

Nas áreas de cultivo convencional, o único fungicida utilizado foi mancozeb, em até quatro aplicações. Não foram constatadas diferenças significativas entre as médias de severidade da cercosporiose em relação ao número de aplicações nos dois períodos avaliados, indicando que o produto não está reduzindo a severidade da doença nos plantios.

Não foram constatadas correlações significativas entre os níveis de severidade da cercosporiose nas áreas de plantio nos dois períodos avaliados, dentro de cada sistema de cultivo. Embora o intervalo entre os períodos de avaliação tenha sido inferior a 90 dias, o inóculo de $C$. longissima produzido no período I, provavelmente, não serviu como fonte de inóculo primário para o início da doença no período II. Na maioria das áreas da Zona da Mata e Agreste de Pernambuco, o cultivo de alface é contínuo, sendo freqüentemente encontrados canteiros com plantas jovens ao lado de canteiros com plantas muito atacadas pela cercosporiose no final do ciclo, motivo pelo qual os inóculos primário e secundário de $C$. longissima estão presentes durante todo o ciclo da cultura.

\section{REFERÊNCIAS BIBLIOGRÁFICAS}

1. CEAGEPE. Calendário de comercialização e outras informações de hortigranjeiros. CEASA-PE - Período 1992 a 2001. Recife: Secretaria da Agricultura, Irrigação e Abastecimento, 2002. 8p.

2. Gomes, A.M.A.; Michereff, S.J.; Mariano, R.L.R. Elaboração e validação de escala diagramática para cercosporiose da alface. Summa Phytopathologica, Botucatu, v.30, n.1, p.38-42, 2004.

3. Lopes, C.A.; Quezado-Duval, A.M. Doenças da alface. Brasília: Embrapa Hortaliças, 1998. 18p. (Circular Técnica da Embrapa Hortaliças, 14).

4. Raid, R.N. Cercospora. In: Davis, R.M.; Subbarao, K.V.; Raid, R.N.; Kurt, E.A. (Ed.) Compedium of lettuce diseases. St. Paul: APS Press, 1997. p.16-17.

5. Savary, S. Épidémiologie de la cercosporiose de la laitue (Lactuca sativa $\mathrm{L}$.) en republique de Côte-d'Ivoire: étude de quelques étapes du cycle épidémiologique. Agronomie, Paris, v.3, n.9, p.903-909, 1983.

6. Zadoks, J.C.; Schein, R.D. Epidemiology and plant disease management. New York: Oxford University Press, 1979. 427p. 